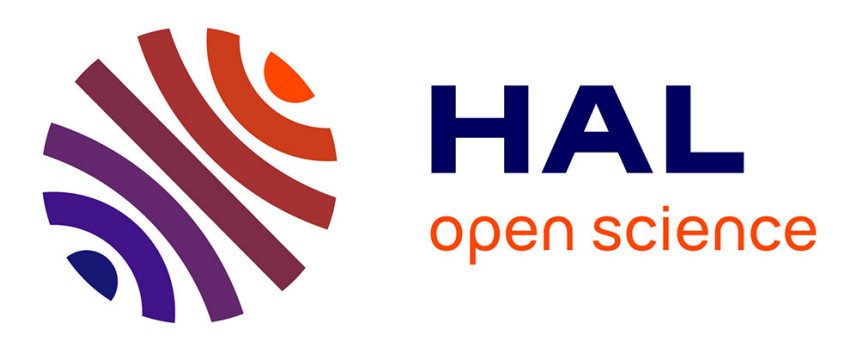

\title{
Institutionalizing Ethical Innovation in Organizations: An Integrated Causal Model of Moral Innovation Decision Processes
}

\author{
E. Günter Schumacher, David Wasieleski
}

\section{- To cite this version:}

E. Günter Schumacher, David Wasieleski. Institutionalizing Ethical Innovation in Organizations: An Integrated Causal Model of Moral Innovation Decision Processes. Journal of Business Ethics, 2013, 113 (1), pp.15-37. 10.1007/s10551-012-1277-7 . hal-01514547

\author{
HAL Id: hal-01514547 \\ https://hal.science/hal-01514547
}

Submitted on 5 Jul 2018

HAL is a multi-disciplinary open access archive for the deposit and dissemination of scientific research documents, whether they are published or not. The documents may come from teaching and research institutions in France or abroad, or from public or private research centers.
L'archive ouverte pluridisciplinaire HAL, est destinée au dépôt et à la diffusion de documents scientifiques de niveau recherche, publiés ou non, émanant des établissements d'enseignement et de recherche français ou étrangers, des laboratoires publics ou privés. 
Institutionalizing Ethical Innovation in Organizations: An Integrated Causal Model of Moral Innovation Decision Processes

\author{
E. Günter Schumacher \\ CEREFIGE-ICN Business School, Nancy-Metz, France \\ David M. Wasieleski \\ Duquesne University, Pittsburgh, PA, USA \\ CEREFIGE-ICN Business School, Nancy-Metz, France
}

Submitted for consideration for publication in the

Journal of Business Ethics

Section Editor: Thomas Clarke

Corporate Governance

Submitted: July 9, 2011 


\section{ABSTRACT}

This paper answers several calls for research to devise a framework for incorporating ethics into a company's processes and strategies for innovation. With the principal goal of organizations being "survival" in the long-term, it is assumed that innovation is necessary in order to realize a going concern. Firms that do not innovate and adapt to rapidly changing business environments are less likely to be sustainable. Thus, it is in a business' best interests to adopt an innovation process for long-term success. We posit that there are two simultaneous sources of innovation and change that are unavoidable and embedded in the corporate landscape. First, we argue for genetically embedded, Darwinian explanations for adaptations that enable an entity's survival. This view is combined with more conventional, social science explanations for change. Our new, comprehensive model of the governance of innovation processes hinges on an organization's long-term orientation, which we argue, is not possible without a consideration of an ethical dimension. The roots of the ethic within innovation are traced from both natural science forces for change, and cultural pressures operating on members of an organization. We present our Integrated Causal Model of Innovation and propose theoretical relationships that will generate numerous avenues for future research in the field.

KEY WORDS: corporate governance, culture, descriptive ethics, evolutionary theory, innovation, natural science, values 


\section{Introduction}

Ubiquitous and unavoidable in nature is the notion that organisms must continuously adapt to their environment if they are going to survive in the long-term. Survival is a basic driver of the natural selection process for all living beings (Darwin, I856; Dawkins, 1987). Designs and traits conducive to the perpetuation of species were "selected for" and those designs which did not adapt and change to the turbulent environment were "selected out." This same logic is often applied to the business organization (Herr, 2009; Frederick, 1995; Pierce and White, 1999). Businesses must constantly adapt and innovate in order to survive in the long-term. This notion of innovation is not limited to product development, but also encompasses the way business is conducted. Managers, as well, are faced with high velocity, changing environments and must alter strategies and processes in order to survive in present-day markets. The long-term going-concern of the business firm continues to be an overarching, principal goal of the majority of rational, market-driven managers (Van de Ven, I986).

If history has taught us anything, it is that sometimes the drive to survive and prosper in business has led managerial decision-makers down single-minded paths that do not take into account the interests and needs of a broad constituency. To facilitate the long-range survival of the organization requires managers to seek ways to sustain organizational effectiveness. From the times of the Industrial Revolution, this has been defined in terms of a profit motive for the owners of the capital. Manufacturing firms have continuously tried to increase productivity and efficiency of human capital and the manufacturing process, through strategies like the manipulation of the supply chain and the invention of more productive equipment (Hoxie, 19I5). While the drive to innovate was present, missing from these approaches was a consideration of ethical norms. As a byproduct, workers were exploited and mistreated. Early management writings focused on ways firms could innovate to increase productivity. For instance, Mary Parker Follett (I924) realized that the worker's perspective should be listened to when trying to improve manufacturing processes and devise more innovative methods for increasing production and ensuring survival (Gehani and Gehani, 2007). Again, even though the workers' perspective was considered, it was not for purposive ethical reasons.

After World War II, this lack of corporate governance extended to other stakeholders as well. Firms in the 1950s became bigger and more productive through various innovations, but the absence of ethical values in the corporate strategic process in part led to violations in consumer safety, and environmental stewardship. During the 1970s and 80s, total quality management and continuous process improvement were developed in Japan to improve the entire manufacturing process, so that companies utilizing the principles would maintain a better competitive advantage (Deming, 1986). By constantly innovating and changing processes, organizations are in a better position to survive. Yet, despite corporate governance efforts to promote the ethical treatment of employees, customers, and other stakeholders, ethical indiscretions persisted, as evidenced by the breadth of banking fraud in the late 1980s. More recently, mega-corporations like Enron innovated and diversified into new businesses in order to grow and survive. This short-term, narrow focus contributed to one of the biggest business ethics scandals in all of history 
(Ferrell and Ferrell, 20II). In this current paper, what interests us about this brief historic background of management theory is the common thread present in each stage and iteration--innovation.

Today, firms have been pressed to be more socially responsible to their stakeholders (Freeman, I994; Wood, I99Ia; Wood and Logsdon, 2002). Socially responsible behaviour by the organization is theorized to be strongly correlated with corporate financial performance, and thus, long-term survival (Griffin and Mahon, I997; Roman, Agle, and Hayibor, 1999). One way for organizations to achieve competitive advantage and maintain their going-concern is to abide by the corporate citizenship principles dealing with social responsibility (Pavelin and Porter, 2008). The European Union in the last decade outlined a very ambitious innovation policy initiative which highlighted "a strong orientation towards CSR" and ethics (Midttun, 2010: 402). The logic behind this position is that the agendas to be socially responsible to various stakeholder groups and the pressures to innovate are not mutually exclusive, but rather are mutually supportive. Managers are called upon to innovate in order to meet these new organizational goals. Corporate social performance is enhanced by processes designed to address the changing demands of stakeholders (Wood, I99Ib). This implies that an ethical dimension exists in the proper management of social relationships for the company.

Our view of ethics in this paper is rooted in an applied or descriptive sense, rather than a normative one, although we do acknowledge that the distinction between the normative and descriptive/empirical dimensions is often difficult to determine (Werhane, 1994). The arguments herein are dependent on the notion that ethics is a discourse among real stakeholders, inseparable from any discourse about business processes. In fact, we reject the separation thesis (see Goodpaster, I99I) that long-term survival of an organization and ethics are mutually exclusive. We are in agreement with Freeman and Harris' (2009) position that business processes need to be seen as another way for individuals to create meaning. Once ethics is viewed as a purely human endeavor, which cannot be separated from business governance strategies or from any discussion involving business and society, then ethics might be thought of as being "concerned with authenticity and change, power and authority, leadership, imagination and the creation of sustainable value" (p.69I). If ethics is truly embedded in any discussion about innovation and change processes, then even more meaningful long-term social contracts can be generated between business and society. Since normative ethics holds little descriptive value, we contend that research in ethics should focus on the examination of the processes used by managers in selecting from a number of different outcomes (Kelly and Dale, 1992). This system of business ethics and corporate governance would then examine how business actions are framed and implemented (Freeman and Harris, 2009).

In this current article, we reject the idea that there exists a dualism between ethics and innovation; and favor instead a "duality" of productive, effective innovations and the maintenance of a principled-view of ethics. Our primary thesis is: In order for business firms to survive in the long-term-their principal goal-the organization's innovation devices will have to include institutionalized ethics processes in order to turn their interest into innovative decision-making. There are stated concerns that innovation processes designs (Brans and Gallo, 2007; Gallo 2004; 
Le Menestrel and Van Wassenhove, 2004), do not fully integrate ethical values. Yet, researchers in innovation management merely identify the need for a discourse about ethics in terms of the development and implementation of emerging models. We posit that ethical values are fully integrated into long-term innovation processes and that ethical values are linked to functional necessity in an organization.

Our paper responds to several calls for research in the area of ethics and innovation. To date, the theoretical link between the two constructs has been grossly underdeveloped. The creativity literature, in particular, is devoid of attention to ethical issues in the process of innovating (Baucus et al., 2008). There is a general lack of understanding of how organizations address ethical issues when attempting to encourage creativity among employees and management. And, more importantly, there is a dearth of knowledge regarding how to design and implement innovation processes with a consideration of ethics. Consistent with this line of inquiry, we first ask: Has a company an interest to integrate an ethical dimension into their innovation devices and processes? Then we follow by addressing, how an ethic becomes institutionalized in innovation.

The discourse presented here in this paper also comes at an important time for corporate governance. For instance, given the increased societal demand for the adoption of socially responsible and sustainable business practices, there is a growing pressure for managers to develop new innovation frameworks to prevent further longterm degradation of the environment (Bloomer, Jagoda, and Landry, 2010). Moreover, our paper responds to a recent corporate call for increased attention to the management of innovation processes. The governance of "the innovation process has not received the attention it should" (p.II4). Firms' innovation processes are profoundly influenced by their corporate governance (Tylecote, 2007). Corporate social responsibility is focused on selfregulation and "represents a regulatory approach that supports innovation..." (Midttun, 2010: 404).

Moreover, we address another plea from the business ethics literature for rules and institutions to be developed which encourage ethical behaviour in the innovation process (Fassin, 2000). This involves a consideration of the rights and fair treatment of all stakeholder groups involved with or affected by the innovation process, and the resulting outcomes of the innovation. Finally, we wish to extend the ethical analysis to include long-term time horizons, multiple levels-of-analysis, and the implementation of the innovation (Farjoun, 2010). Our position is that ethical consideration is fully compatible with the process of innovation. In order for an organization to survive in the long-term, management must innovate and govern processes in order to adapt to a changing environment. On one level, managers must create a work environment that creates "paths to achieve innovative solutions that answer to unimpeachable ethical standards (Baucus et al., 2008: II3). On another level, corporate governance mechanisms need to promote and maintain stability within the organization. We argue that a necessary condition of the principal goal of long-run survival is a consideration of ethics. Thus, the innovation process of a company with a long-term survival goal must have an embedded and institutionalized concern for ethics and a process for encouraging ethical behaviour among the stakeholders of the innovation. 
The structure of this paper is as follows: We begin by laying out the theoretical backgrounds of the driving forces behind our model of ethical innovation. We present the Integrated Causal Model which will bring together two seemingly disparate approaches to understanding the ethic embedded in innovation and change processes. First we lay out cultural explanations for innovation from the standard social science model of human behaviour. Implicit in this approach are ethical values and their translation and institutionalization into the ethical climate and culture of an organization. The other source for change we present is based in the natural sciences. Natural values derived from evolutionary and thermodynamic forces are described. Then we present and discuss our model for ethics and innovation which illustrates the process of translating a firm's survival interest into decisions regarding innovation and change. The convergence of the two approaches will demonstrate how ethics is instilled in the process of change, as long as the organization maintains a long-term orientation.

\section{Background}

To address this important goal of integrating an ethic into an organization's innovation processes, we take a novel approach of bringing together two disparate views of change processes. In this article we advocate an Integrated Causal Model (Cosmides and Tooby, 2004; Wasieleski and Hayibor, 2009) of innovation and change. The Integrated Causal Model (ICM) brings social science constructions of behaviour and process together with insights from natural science theories to draw a much more comprehensive portrait of the innovation and change process which includes an ethical dimension. This is an alternate view of human behaviour to the Standard Social Science Model (SSSM), which derives all conceptual relationships from direct observation. This positivist approach focuses more on one set of explanations for human behaviour and processes-those found in sociological, cultural, and psychological domains (Tooby and Cosmides, I992).

The ICM, which has its origins in evolutionary theory, assumes that human behaviour is largely shaped by recurrent adaptive challenges of the ancestral world. To survive a complex environment, individuals developed detailed skill sets, through natural selection, that enabled them to adapt to a constantly changing world. These specializations not only affect biological features of individuals, but also influence the content of cultural elements that are acquired from, and transmitted to other individuals which is reflected in the design and operation of evolved, innovative problem-solving circuits (Bonner, 1990). Thus, culture is not rejected by this view, but is part of something larger. So, current human behaviour is to a great extent shaped by cultural norms, but these norms were themselves shaped (in part) by evolutionary forces.

In other words, we take a duality approach to integrate ethics and innovation into normal organizational functioning imperatives (Farjoun, 2010). We believe that if an organization institutionalizes (through corporate governance mechanisms) an ethic or set of ethics principles characterized by long-term stability and reliability, ethics and innovation are wholly compatible and complementary. In effect, the dualism classical economic model is rejected in this present paper as an approach to understanding innovation processes. Companies do indeed wish to 
be reliable and stable over time, yet are expected to be innovative and proactive when it comes to dealing with changing demands from the market (Weick, 1979). While the pursuit of both stability and change seems paradoxical, we contend that stability cannot be achieved in modern-day business without the ability to innovate and change to new stakeholder and market challenges. Traditional organizational theories dominating the management paradigm and the SSSM, in general, treat stability and change as mutually exclusive concepts, which has substantively limiting effects on the processes and models that are derived from these theories (Pfeffer, 1997). Our new approach advocated in this paper treats organizational innovation and long-term stability as a duality and integrates two distinctive paradigms (evolutionary theory and organizational culture) to achieve a more complete understanding of successful innovation processes. We believe the critical juncture where both approaches meet is with ethics. It is with ethics that we base our integration and design for a dynamic model of innovation.

Being aware that the term "ethics" can be used for different purposes in the business world and that the interdisciplinary approach of this paper asks for a high degree of precision - in order to avoid confusion associated with the nature of arguments and of the different levels of action - we prefer to specify the following points:

First, this conceptual paper is of descriptive nature and prepares for a future empirical investigation. So we will employ in the following a) the term "ethics" to designate an academic research discipline, and b) we will choose the approach of "descriptive ethics". Closely related to anthropology, sociology and psychology (DeGeorge, 2008; Rich, 1984; Stückelberger, 2002) descriptive (or "comparative") ethics does not examine what should be done from a normative, moral philosophical point of view, but how moral systems, codes, practices, beliefs, principles and values work and can change.

Second, the research subjects, just mentioned, of such a descriptive ethics, will be summarized in this paper with the term ethic. For us ethic can be defined as a system of moral attitudes and behaviour encompassing concepts, standards and rules which find their expression in informal elements (customs, manner, tradition), and in formal, written elements (codes, laws, contracts). We posit that both the informal and formal elements of the ethic are driven by cultural forces as well as natural ones.

Third, following the common use in English language, the adjective "ethical" will be employed as well for designating a reference to a specific academic research discipline as a word establishing a link to elements of morality. On this background the ICM can be considered as a model which will be used as integrated into a descriptive ethics

- perspective in order to answer one of the numerous questions of corporate governance (i.e., which positive link exists (in the long term) between innovation and ethic, and how internal procedures should efficiently mirror or reinforce this link).

\section{Social Science Perspectives on Change}

Focusing on the "cultural" forces leads social scientists to discover two main traditions in this academic field: one tradition which tries to disclose general and permanent elements in human society and, another tradition which 
focuses on its particular and transitory components. Here we see two time dimensions-long and short-term. For our purpose in this paper it is sufficient to mention that the first tradition represents the forum for research perspectives like functionalism, structuralism and the systems approach (at the origin particularly with Spencer, I877; Durkheim, I893/I967; Pareto, I902; and later particularly with Parsons, I95I; Malinowski, I944/200I; Luhman, 1966), which continue to provide important research perspectives in the present period. The second tradition characterizes the classical approach of historical studies and the effort of other disciplines in social science highlighted by the distinction offered by Immanuel Kant between "Kultur" and "Zivilisation" (Kant, I783) - to analyse particular and transitory elements of behaviour by using a "cultural" perspective, employing the notions of "culture" and "cultural" as an alternative to "civilization", "society" and "social". So for example, we can find in the field of anthropology the distinction between "social anthropology", following the structural-functionalist tradition and the "cultural anthropology", which serves as a broader notion for all alternative approaches (Schumacher, I985: 4II).

Even if these terminological distinctions are not generalized in the social sciences, where the notion of culture continues to be employed sometimes as a general term encompassing societies and/or civilizations, they seem useful for the purpose of our Integrated Causal Model for the following reason. In this model the question of "permanent" elements of human societies is stressed by the evolutionary view of natural science. So the terminological distinctions between culture and society/civilization will help to understand more easily to what extent social science findings reinforce the natural science argument of permanent elements influencing human behaviour, and to what extent social science research reveals particular and transitory elements, which represent elements of natural variety and change. This permits us to more easily sort through different scientific perspectives focusing on the phenomenon of stability or change, (phenomena closely linked to our question of innovation and ethic), and to integrate them coherently in our model of organization level change.

So we will examine at first, how the question of stability and change can be treated from a more structuralfunctionalist perspective with the social sciences.

\section{Organization and Functional Imperatives}

A recent methodological study in the field of social science, carried out by A. Fusari (2004), carefully examines, among other aspects, the question of permanent elements in human organizations. Permanence, logically speaking, involves duration. Fusari questions the link between duration, change, choice and necessity, underlining the crucial importance of distinguishing all these aspects (Ibid: 517). Following Parsons (Parsons, I987; Parsons and Smelser, 1970), he shows that permanent elements in society take the form of permanent necessities or of "functional needs" (Ibid: 5I9). By characterizing them as "necessary conditions of efficiency" (Ibid: 5I9) and not as sufficient conditions, he makes it clear that there does not exist a determinism or automatism which would imply that these 
organizational needs are always satisfied in the real world. As with the natural science literature (presented later) also social science observes here permanent tendencies, but not their permanent realization.

These functional needs are regularly called "functional imperatives" (Ibid: 505). Even if these imperatives are considered by sociologists as permanent, one mustn't draw the false conclusion that their "translation" into the evolving society is permanently realized in the same identical manner. This translation depends on the "general conditions of development" (Ibid: 5I8), which themselves change throughout history. An example of these functional needs would be to accommodate the integration of new information technology systems and business communication. This can be accomplished in a variety of ways by company executives. It is even possible that a given society or organization does not follow, for different reasons, these imperatives. In such a case the existence or survival of the organization itself is threatened. Functional imperatives aid in the survival of a society or of an organization. We emphasize that the "survival" orientation or interest of human societies and organizations can be grounded in the functional logic of systems without being obliged to consider a human organization as a biological organism. Social and natural sciences come here to the same conclusions despite the application of different methods and concepts.

If functional imperatives represent one of the classical structural-functionalist explanation of permanent and general elements of society, providing stability to social organization, the question remains where change has its place in such a perspective. We can observe at least two places. The first one concerns the translation of these imperatives into reality depending from the general conditions of development of the society concerned. These translations change with the development conditions. The second place for change can be found inside the functional imperatives themselves, i.e. one of these imperatives can express the need for change. (Munir, 2005). One functional imperative of modern dynamic society is the work that is done by innovators (Fusari, 2004). Change can be part of these imperatives themselves, and innovation (as a functional imperative), takes the role here of a stability provider. In this context one has to be prudent with the conclusion that stable non dynamic societies are composed only by nondynamic sub-systems or organizations and that change could arrive only from outside. H.D. Seibel demonstrated and validated in his empirical research in Africa and Europe that non-dynamic, "traditional" societies regularly encompass dynamic, innovative sub-systems or organization, whereas dynamic "modern" societies count a lot of nondynamic, innovation-hostile organization among its components. (Seibel, I980).

Despite a general consensus in social science concerning the existence and importance of a certain link between stability and change, a pure structural-functionalist approach, combined with a dualist perspective, seems to have failed to precisely draw this link, and its causal connections. Alternatively, the duality perspective presents a promising way for achieving a deeper analysis of the stability-change relation. It is presented in the following section. 


\section{Stability and change}

According to Farjoun, a dualistic perspective normally works with "...clear-cut and decisive contrast, a well-defined boundary (2010). This often becomes synonymous with opposition and potential conflict” (Ibid: 203). For him, such a perspective is not able to explain sufficiently how organizations manage in the real world to reconcile stability and change in order to survive and to prosper, following by this way objectives which he designates explicitly as "imperatives" (Ibid: 202). His solution is to change the point of view and adopt the perspective of duality. This

perspective "...resembles dualism in that it retains the idea of two essential elements, but it views them as interdependent, rather than separate and opposed” (Ibid: 203). Adopting such a view-point “... social theorists ... (e.g. Elias, I99I; Giddens, I984) can maintain conceptual distinctions without being committed to a rigid antagonism or separation” (Ibid: 204).

Farjoun employs the duality, or "dual" perspective for the resolution of the stability-change paradox, maintaining that "...stability and change are fundamentally interdependent--both contradictory and complementary" (Ibid: 203). This complementary notion means that change and stability can be "... mutually enabling and constituent of one another" (Ibid: 205). In order to conceptualize this link further he adopts the exploitation-exploration model (March, 199I) and distinguishes between the process dimension and the performance dimension that are both present in change processes and in the maintenance of stability. The process dimension, to which he also attributes practices and forms, is designated with "mechanisms", and the performance dimension, which includes the observed objectives, is designated with "outcomes" (Ibid: 206).

On the base on a comprehensive and careful analysis of the management literature, Farjoun identifies the typical mechanisms and outcomes of change and stability. The mechanisms characterizing stability are: habits, routines, institutions, discipline, tight coupling, limits, commitments, control, and low variance; those characterizing change are: search, mindfulness, redundancy, openness, preoccupation with failure, imagination, and variety. The outcomes typical for stability are: continuity, low variance, predictability, regularity and reliability; those typical for change are: adaptability, high variance, innovation, and flexibility (Ibid: 206).

This conceptualization allows us to show that one can distinguish four situations: I) the situation where stability mechanisms and outcomes combine (exploitation configuration of March, 199I); 2) the situation where change mechanisms and outcomes combine (exploration configuration of March, I99I); 3) the situation where stability mechanisms are combined with change outcomes, (i.e. stability enables change) and; 4) the situation where change mechanisms are combined with stability outcomes, i.e. change enables stability. The first two situations form an opposing relation, whereas the relation of last two is characterized by complementarities (Ibid: 206). By this approach Farjoun succeeds to demonstrate that change and stability are not always in opposition, but that change can be compatible with stability, and even enable it, as stability mechanisms are -to a certain degree - necessary for change. 
Returning to the discussion of how the stability-change link is treated in social science, we can see that Farjoun's analysis demonstrates a way to open up structural-functionalist based approaches to a deeper analysis of this link. His examination shows that change is compatible with duration and necessity ("imperatives"). Another aspect, however, linked in the social science debate to the phenomenon of change is the aspect of choice, representing the fourth element of Fusari's distinctions. Indeed, change has been in the past very often associated with choice, creating sometimes an opposition to necessity, which itself has been linked without any logical or empirical obligation automatically to a deterministic interpretation of social processes. This association of change and choice, combined with the conclusion that choice and permanence are not compatible, has led many social scientists to the assumption, that change (i.e., choice) is not easily compatible with duration. This leads us to the next section.

\section{Corporate Culture and Grand Options}

As mentioned above there exists an enormous variety of approaches in social sciences, which are committed to a nonstructural-functionalist perspective for examining particular, transitory elements (i.e., of a short-term nature) of organizations. The "cultural" approach, seen as an alternative to a "civilization" view-point (as explained by Kant), represents among these different theories and concepts a very important research tradition. The different currents within this tradition in social science are also found in the corporate culture literature (Schein, 1985; Sinclair, 1993). In business firms, organizational culture is "the pattern of basic assumptions that a given group has invented, discovered, or developed in learning to cope with its problems of external adaptation and internal integration..." (Schein, 1985: 9). These assumptions are taught to other members of the cultural group as the way the environment should be perceived. The conditional rules of the group—deontic and permission—are generated by culture. Beliefs and values are learned from the group and spread to all the new members of the group through socialization (Taormina, 2009). The culture of the organization affects the perceptions of reality of its members and the

decisions that are made. Within cultural norms that guide behaviour, we find the ethical dimension as manifested by ethical values. These enduring beliefs in an end-state or an instrumental process guide, sustain, and motivate behaviour (Rokeach, 1973).

Generally there are several main elements that comprise an ethical organization. In other words, for an organization to institutionalize ethics into its main processes, there need to be certain features present in the corporate culture and governance of the organization that demonstrate a commitment to ethics. This is normally viewed as a precondition for institutionalization of ethics to take place (Agle, Mitchell, and Sonnenfeld, I999; Kirkpatrick and Locke, I99I). The organization must establish a corporate ethics policy "which provides a statement of the norms and beliefs of an organization (Carlson and Perrewe, 1995: 83I). The goal for managers is to develop an institutional logic that includes ethics. Institutional logics are "socially constructed, historical pattern(s) of material practices, assumptions, values, beliefs, and rules by which individuals produce and reproduce their material substance, organize their time and space, and provide meaning to their social reality" (Thorton and 
Ocasio, 1999: 804). Once such a reality includes a consideration of ethics, it is more likely innovation processes will automatically include a normative dimension.

Commonly, organizations adopt ethics codes to provide a more ethical foundation for firm processes. (Kapstein and Wempe, 1998). Codes are formed to help promote the institutionalization of ethics within an organization's culture (Adams, Taschian, and Shore, 200I). They are normally part of a much broader corporate governance program to institutionalize certain company values with which all stakeholders of the organization can identify. Deeply rooted ethical values will influence how employees at all levels perceive the nature of the organization itself (Valentine and Barnett, 2002). The institutionalization of ethical values through socialization and adoption of ethics codes has become much more widespread in recent business history, as more companies find it necessary to establish a strong ethical culture (Weber, Gerde, and Wasieleski, 2008).

Corporate culture research does not frequently frame the choice and change question in a long duration perspective. They do so, as they do not systematically distinguish between permanence and long duration or do not distinguish, like Fusari, necessity and duration. Indeed, permanence implies long duration, but not every long duration phenomenon will be permanent, and necessity pushes towards duration, but not every durable organizational element is due to necessity. For example, some durable elements are unintended byproducts of the culture. Not distinguishing among these phenomena and ignoring their complex causal interconnections, often researchers associate regularly change, choice and short or middle term.

Recently, Fusari (2004) explored the scientific fruitfulness of disconnecting commonly accepted and presumed links of the aforementioned phenomena. Like Farjoun with his duality approach, Fusari succeeds with his distinction among the phenomena of duration, change, choice and necessity, to help organizational research to leave sterile opposing or mutually excluding perspectives. For our purpose, Fusari's concept of "Grand Options" (Ibid: 524) holds our attention.

"Grand Options" are defined by the author as:

"...the basic ideological choices around which social fabric revolves, which is structured and integrated, .....These key ideas define the fundamental physiognomy of the social system, they are its supreme guiding criterion, the inner fire that warms its hearth” (Ibid: 524).

These Grand Options have been chosen once in a long process and are not the logical result of necessity and functional imperatives. On the contrary, they can be developed independently from functional imperatives and necessity. Fusari claims that they cannot be of long duration, if they are not in the long run consistent with these imperatives (Ibid: 525). However, the fact that Grand Options belong to the field of choice and not to the field of necessity, does not imply that these options are of short-term nature. Indeed, they are of long-term nature, as they “... are the product of very lasting elaborations and cannot be overturned by sharp, sudden decisions, but only removed gradually over a protracted transition period" (Ibid: 524). The existence of Grand Options reveals that choice does not automatically imply change in the short-term. We can observe the phenomenon of choice even without change. 
Reflecting again upon our principal goal of structuring our Integrated Causal Model (i.e. the innovationethic compatibility), we can now draw the following intermediary conclusions:

I. In examining aspects of innovation, it is important to distinguish and separate the following aspects: the mechanism and the outcomes of innovation, the change aspect and the choice aspect of innovation, and finally the degree of duration linked to an innovation.

2. For the analysis of the ethic-phenomenon it seems promising a) to distinguish ethical mechanisms and ethical outcomes, b) to reveal which ethical values results from necessity and which ones from choice, and c) to disclose which degree of duration is characteristic for ethic.

The grounding of an ethic and its values is another way to ask one of the questions of this study: how to integrate the ethical dimension in a causal innovation model, where natural and social science findings are coherently combined. In other words, we have to examine if the ethic is grounded in nature and/or society. For this purpose we distinguish ethical values which are grounded in society and culture, which we will designate as "social/cultural" ethical values, and those grounded in nature (evolutionary theory), which we will call "natural" ethical values. We first discuss the former type in the next section.

\section{Social/cultural ethical values and necessity and choice}

"Ethical" values are the deeply held beliefs which provide guideline and reference for an ethic, i.e., as defined above, for a system of moral attitudes and behaviour encompassing concepts, standards and rules. Stückelberger and the German-speaking academic tradition (e.g. Rich, 1984) ground ethical values in "fundamental premises (axioms)" transformed in "fundamental values (criteria)" (Stückelberger, 2002: 24), which seem to describe the area of “ontological imperatives" (Fusari 2004: 520). Fundamental premises are based on experience and are not exclusively substantiated on rational grounds (Stückelberger, 2002: 25). For example, the desire to live would be a fundamental premise of survival. Fundamental values are independent of context (Ibid: 25), as are apparently ontological imperatives, because they "...do not vary with the general conditions of development and hence are not pushed to impress themselves on in the course of history in a way or in another..." (Fusari, 2004: 52I). Using the above example, the fundamental value associated with the premise of "I want to live" is "survival" (or, as we will see later, economizing). We see these fundamental values expressed in ethics codes of organizations from corporate governance, as discussed in the previous section.

To further clarify the distinction, we must determine if the "necessity" of a condition is, on one hand, considered as an objective fact of nature, independent from human awareness and action, and/or as a general, intersubjectively shared perception of a permanent and general fact from reality, or if it represents a not generally intersubjectively shared perception of a fact, perceived for a limited period of time as "necessary". The first case reflects the constellation which Fusari subsumes under the category of "necessity", whereas the latter corresponds to his category of "choice". Systems of moral attitudes and behaviours encompassing concepts, standards and rules, (i.e., 
ethic) does not change in the short or middle term. Logically, an ethic has clearly a long-term character and ethical dimension implies a long-term horizon. Even if this observation seems to be evident and somewhat banal, it discloses an aspect of ethic which is of crucial importance for a causal analysis of the innovation-ethic decision process. If this long-term character of ethic implies permanence and necessity, is it also compatible with change. The distinctions of ontological imperatives, functional imperatives and grand options permit us to position the ethical dimension within human culture, and to specify its fundamental links to permanence, necessity, change, innovation and choice.

Ethical values are present at the level of ontological imperatives in the form of fundamental moral values. At this level the ethical dimension is consequently independent of the context and of the general condition of a society. This part of ethic can therefore be of permanent character, especially if ontology is rooted in a scientific philosophy. Ethic is not characterized by change or innovation, as are stable fundamental values shown in the different religions and wisdoms (Smith, 199I). Choice, however, is not excluded because philosophies and religions exist within fundamental values and can be chosen by man/women and are not all the time imposed to the people against their free will (Weaver and Agle, 2002).

At the functional imperatives level, Fusari observes "...that some ethic aspects may represent (be derived as) functional imperatives..." (Ibid: 520). This means that the ethical dimension at this level reflects organizational necessity, establishing value coherence between fundamental ethical values and the organization survival value. Ethic is so linked to necessity, which in the non-deterministic view of Fusari does not mean that people will automatically respect it. The ethical dimension is furthermore linked to the permanence and the general/universal character of functional imperatives.

At the level of the grand options the ethical dimension is present, as well. As "basic ideological choices" grand options represents "specific value-ideological choices" (Ibid: 524), which reflect the "ethic-ideological aspect" (Ibid: 5I8) examined by Parsons in a purely functionalist perspective. Due to the specificities of grand options ethic is here integrated in a context of choice-long-term (but, non-permanence) and particularity. Moreover, on this level Fusari positions non-adaptive, "real" innovations. He distinguishes between "ideological and value innovations, relative to the sphere of ideas, values and world views; and technological innovations, which in an advanced state of knowledge stem from the application of the appropriate sciences to problems of life" (Ibid: 526). Technological and economic change models "maintain that static efficiency and specialization could not co-exist with the dynamic efficiency required for innovation" (Farjoun, 2010: 202; from Abernathy, 1978). Ethic is related to these innovations in a different manner. In the first case ethical values can themselves become the subject of change, which provides them, at this level, a relative character. In the second case, different relations between (technological) innovation and ethic are imaginable, either as complements of one another, or oppositional. It is predominantly at this level that our ICM will elucidate the innovation-ethic link. 
In evaluating these observations in this section, we see that the ethical dimension is present at different levels of analysis. We discover that it would be totally unjustified to assign to ethic, because of its philosophical base and its long-term character, exclusively permanence, choice and universality, and to deny its potential of non-permanence, particularity, respect of necessity and innovation-compatibility. The ethical dimension is integrated in a complex system, characterized by necessity and choice. Ontological imperatives will not automatically be translated into reality, but their "triumph is warranted only if evolutionary process is not obstructed, so that they will be transformed sooner or later into functional imperatives..." (Ibid: 52I). Concerning the likelihood of grand options existing for a long time and being able to resist technological, environmental, and social changes, he stresses that they “...resist if they agree with functional imperatives, mainly those concerning value premises” (Ibid: 525). We claim that these value premises are rooted in another source as well. Now our attention turns to lessons from natural science.

\section{Natural Science Perspectives on Change}

\section{Evolutionary Biology}

Evolutionary theory describes a detailed process of how species are continually designed and developed (Chambers, 1844; Darwin, 1859). Darwin himself referred to his theory as a doctrine of "modification" (445). Evolution is an adaptive theory; in other words, features of living organisms are the result of adaptations to the environment (Futuyma, 1979). Derived from Darwin's theory, evolutionary biology "consists of the logically derivable set of causal principles that necessarily govern the dynamics of reproducing systems" and that are responsible for the properties that compose a living being (Tooby and Cosmides, 2000: I I86). Evolutionary biology also identifies the principles that govern which kinds of organic features are selected for, and which are selected out. Various environmental pressures that jeopardized survival faced our ancestors. To deal with these adaptive problems, certain structures are selected for, which enable organisms to cope. Thus, the form of the organism follows the function that that particular structure is designed by natural selection to serve. In other words, evolution does not select for behaviour. Instead, it "only selects for mechanisms that produce a behaviour or predispose" an organism to that behaviour (Wilson, 1993: 127). Successful features are those which allow an organism to propagate. Natural selection—evolution's process for choosing the structures that solve adaptive challenges—engineers a fit between the design features of the organism and the function necessary for survival.

Evolutionary biologists work backwards by discovering and defining adaptive problems facing our ancestors and trying to deduce the physical structure needed to solve those dilemmas. Often times, there is more than one way to solve a dilemma, however. "But the more precisely you can define the goal of processing - the more tightly you can constrain what would count as a solution-the more clearly you can see what a program capable of producing that solution would have to look like" (Cosmides and Tooby, 2000b: 1259). Essentially, modern evolutionary biology "constitutes... a foundational organism design theory, whose principles can be used to fit together research 
findings into coherent models of specific cognitive and neural mechanisms” (Tooby and Cosmides, 2000: II86). A clever and useful way of viewing the evolutionary process in general is to think of it as an algorithmic design (Dennett, 1995). Algorithms are mechanical procedures or instruction manuals of evolution. "An algorithm is a certain sort of formal process that can be counted on-logically— to yield a certain sort of result whenever it is 'run' or instantiated" (p. 50).

\section{Natural Systems}

In open systems, there exists a continuous exchange of energy in the environment. Transformation of energy from one form into another occurs in an ongoing cycle (Baskin, 1998). In the long-term humans have become adept at staving off the complete degradation of energy through short-run management techniques that preserve order and sustain life. Business organizations are a natural manifestation of life's anti-entropic tendencies (Frederick, 2004). Definitions of systems and their boundaries and the evaluation of energy flows in isolated systems make up the main foci of the laws of thermodynamics (Ruth, 1993: 5I). "It is the purpose of thermodynamics to find general relations among the thermodynamic coordinates which are consistent with the principle of the conservation of energy..." (Zemansky, 1937: 23-24). Conservation of energy and the stabilization of coordinates are impossible in the longterm. Technically, when no external force in the environment and no internal transformation of energy are taking place, the system is said to be in mechanical equilibrium. This is a short-lived phenomenon in nature, indeed. Rather, as time progresses, natural systems are subject to continuous change. The transformation of energy by an organism from a useful form to a form which provides less utility for the organism leads to a state of change.

\section{Entropy and Thermodynamic Equilibrium: The Second Law of Thermodynamics}

These natural processes as dictated by the laws of thermodynamics are irreversible. Neither the organism, nor the environment in which the organism exists can return to their initial states (Zemansky, 1937). The procession from the organism's original state to its final state is unavoidable. The final state is thermodynamic equilibrium. This is the point at which a system has exhausted all of its change potential. The means to this end is the process of entropy. Entropy is "a quantity that relentlessly grows with dissipation and attains its maximum value when all the potential for further work is spent" (Coveney and Highfield, I990: I5I). Thermodynamic equilibrium is the point when entropy has reached its greatest quantitative value in a given system. "Increasing entropy is a sign of the progression of time” (p. 149). Essentially, entropy represents a system's capacity for change and continuously increases through time. The second law holds that physical systems move away from organized states to states of maximum disorder (Feynman, Leighton, and Sands, 1963). 


\section{Organizations as a Temporary Solution: The First Law of Thermodynamics}

Not all hope is lost. The principle of energy conservation applied to a thermodynamic system and its environment is the first law. The First Law of Thermodynamics states that "energy will always be conserved in a physical process..." although it does get converted into different forms (Coveney and Highfield, 1990: 150). The fact that living systems are able to continue to work and operate, despite processes dictated by the second law, suggests that a source of internal energy exists to sustain closed systems in the short-term. Relevant to our purposes in this present paper is the fact that these natural laws factor in profoundly to systems in business organizations. Innovation is one way for businesses to stave off degradation of current practices. Put another way, living systems are able to self-create and renew themselves. Life contradicts the second law by holding entropy at bay, albeit temporarily. Selforganization is the process underlying non-equilibrium thermodynamics which provides the means to which organized structures form in the midst of increasing disorder (Coveney and Highfield, 1990; Petzinger, 1999). Essentially self-organization creates functional order, which can be likened to the social science notion of functional necessity.

Functional order as described in the first law does not spontaneously manifest itself, however. Darwin recognized the fact that life forms are subject to forces which cause ultimate degradation. He spoke of self-contained organization within individual members of a species in terms of the preservation and accumulation of variation. "This improvement inevitably leads to the gradual advancement of the organization of the greater number of living beings throughout the world" (Darwin, I859:122). According to Tooby, Cosmides, and Barrett (2003), Darwin's theory of natural selection was the solution to the thermodynamic problem outlined by the second law. Physical systems are organized in such a way as to allow themselves to maintain, propagate, and survive. Thermodynamic systems analysis can be applied to machines, biology, or economic systems. "An economy receives material and energy inputs from its environment and provides outputs to its environment" (Ruth, I993: 48). By virtue of the second law, efficiency of energy transformation is constrained by the growth of economic and ecological systems. These methods can be translated into a set of naturally held values that are engrained in both individuals and organizations, as we reveal next.

\section{Natural Ethical Values Linked to Functional Necessity}

Work analyzing the structural design of organizations can be partially explained by natural science models of change (Pierce and White, 1999). Other organizational process models have used the natural values approach to reinterpret their functioning. For instance, the Corporate Social Performance model was reworked according to 'naturological' principles in an effort to inject a normative element into Wood's (I99Ia) systems approach (Swanson, I995). Here we apply natural values to innovation processes. Natural master value sets dominate the functioning of business institutions. Values "emerge from and reflect human experience in coping with nature" (Derry, Fort, Frederick and Hauserman, 1999). These values are evident in and guide business practices, but were not invented by business 
practitioners. Rather, they are natural processes that every living organism or group of organisms abides by (Frederick, 1995).

One such value set is generated out of the process of organizing structures for survival. Economizing is the process of taking energy from one's environment and transforming it into useful work (Frederick, 1995: 3I). It is essentially the natural process offsetting the end-state equilibrium condition, outlined in the previous section. The second law allows for temporary interruptions of the entropic process (self-organization), which is called economizing (Frederick, 1995: 38). Natural selection informs economizing. "Selection is the only known counterweight to the tendency of physical systems to lose rather than grow functional organization" (Tooby, Cosmides, and Barrett, 2003: 858). Evolutionary biology demonstrates that the best at staving off entropy by selforganizing, or economizing, will propagate its species.

Businesses economize by acquiring resources from their environment and efficiently turning them into productive value. Firms must innovate to be able to economize (Frederick, 1995) and maintain self-organizing structures resilient to market and political forces, for long-term survival. It is a core business value required for organizational growth, sustainability, and systemic integrity (Derry et al., 1999). "As values, they are the core beliefs of business practitioners, and they are the central directing behavioral standards for business conduct" (640). Indeed, organizations must innovate in order to survive. Adaptation is the vehicle through which firms survive. These tendencies for organizations to economize and create self-organized structures that adapt to the changing environment in an open system are unavoidable and naturally generated (Petzinger, 1999). All "living things harbor an impulse to economize as a bulwark against the universal propensity toward...entropy" (33). Innovation is not optional for organizations to survive; it is an "absolute necessity designed to solve problems and cope with complex and changing environments" (Herr, 2009: I64).

One other critical aspect of human behaviour that affects the propensity of individuals to innovate in order to survive and realize a long-term going concern relates to the values and normative orientations associated with technology. Technology here is not meant to only refer to the machines and technical advancements that ubiquitously facilitate and interfere in our lives. Rather we refer to technology in the sense intended by Frederick (1995) as "the entire array of technical manifestations..." including, "behavioral features, organizational patterns...that can trace their functions and operations to a symbolic process in genetic systems and expressed in socio-cultural forms" (I72). Technology is a vehicle by which individuals or organizations economize. But within this vehicle lies a normative base. Frederick maintains that there exist values within technology that guide how individuals and organizations economize in an open system. These values are generated from both culture and nature. The same evolutionary and thermodynamic processes discussed in this article govern the logics and values associated with the innovative technical manifestations that aid in long-term survival. Naturally speaking humans innovate and adapt by rite of the technological tools developed over time. Thus, technology is pragmatic as it serves the purpose of creating solutions to adaptive problems. The emergence of technology is cumulative and progressive; 
that is, sequences of technical development accumulate as time progresses (Frederick, 1995: I89). Techno-symbolic values are embedded in human nature as a means for reasoning symbolically and innovatively to transform elements of the environment. An individual's ability to think abstractly is directly related to the "ability to create culture and moral norms" (654). Thus individuals innately innovate through these techno-symbolic values. This is consistent with the technological systems perspective from Carlsson and Stankiewicz (1995), which is rooted in the social sciences. This perspective considers technological systems as a network of actors who interact within a certain socioeconomic context and institutional infrastructure. It is acknowledged that "techno-economic selection takes place in a socio-cultural environment" (Midttun, 2010: 404).

\section{Transforming Business Interest into Innovation Decisions: The Ethic-Innovation Model}

With the interest in the company's long-term survival as the principal goal of management from business' earliest days to present day, one process has played a part every step along the way-innovation. Innovation systems are interrelated and interacting sets of organizations, managers, owners and institutions (Carlsson, 2006). Innovation is extremely important for organizational effectiveness (Janssen, Van De Vliert, and West, 2004). For technologically driven innovation, these processes involve both structural factors and systems functions (Bloomer, Jagoda, and Landry, 2010). The structural factors consist of institutions generated through corporate governance (Suurs et al., 2010). "Institutions provide guidance through various mechanisms such as laws and regulations" (Bloomer et al., 2010: 117). Innovation can and does take different forms, depending on the culture created by the actors involved. It is well established that for organizations to adapt and survive in the long-term, innovation has to be fostered among the stakeholders of the organization, but also in the processes used by management. Innovation systems within organizations involve the coordinated management of actors, networks and institutions for the adaptation of processes to fit within a particular environment (Jacobson and Bergek, 2004).

The recent trend for companies is to innovate openly (Gronlund, Ronnberg Sjodin, and Frishammar, 2010). Open innovation is defined by Henry Chesbrough as, "the use of purposive inflows and outflows of knowledge to accelerate internal innovation, and expand the markets for external use of innovation" (Chesbrough, Vanhaverbeke, and West, 2006: I). It allows for the shared benefits of the knowledge transfer. For example, to compete in the I/T sector and regain market share, Cisco Systems innovated by adopting technologies from the outside. They created partnerships with firms and even invested in startup companies to keep up with the industry. Long-term growth became emphasized and the maintenance of fair and mutually beneficial stakeholder relationships was sought after. For for-profit firms, long-term growth is achieved by realizing that short-term profits may have to be sacrificed in favor of long-term survival. The stakeholders of an organization will expect future benefits of the innovation (Tylecote, 2007).

In the systems of innovation literature, there is a "broad focus on the social organization of the innovation process whereby it implicitly also corresponds with the CR agenda” (Midttun, 2010: 403). Thus it is acknowledged 
that the needs of the stakeholders are indeed an important factor in the development of an innovation process. The desire to survive may have a biological basis, but it is not enough to generate a successful innovation strategy—one that maintains a long-term time vision. Cultural elements found in organizational institutions must be designed to focus on the proper treatment of stakeholders of the open innovation. It is "possible to identify institutional characteristics of...governance systems that have contingent value-that are more or less conducive to successful innovation" (Tylecote, 2007: I462). Corporate governance strategies that deliver value to society will lead to longterm growth (Clarke, 2007). We will show how this can be true in our model next.

\section{Integrating the Approaches: The Duality of Natural and Social Sciences}

As developed above, two elements are of great importance for the relationship between innovation and ethic. On one hand, the long-term survival goal - representing the common reference point for innovation and ethic - implies the dimension of time and underlines the process dimension of the research subject. This logically reflects the chosen evolutionary and cultural perspectives described in this article. As a second element, we underline that it seems more promising from an empirical point of view to analyse the innovation-ethic relationship by using the duality concept and not the concept of dualism. The duality concept can coherently be integrated as such into a probabilistic causeeffect analysis, if it is used, like in a path diagram, to localize the different bifurcations reflecting the non-monocausal nature of duality.

In order to offer a coherent and operational base for empirical research, our model combines both elements (i.e., the process dimension and the duality character). A coherent combination of both has to be set up within a cause-effect frame, the classical perspective normally adopted in the sciences, when it is necessary to analyse a process. Indeed, since the first written reflections on causality in the Western world (Aristotle's Metaphysics, transl. by W.D. Ross, 2006), temporality and causality have been thought to be linked, because causality - defined as relationship between an event A, the "cause", and another event B, the "effect", which is the consequence of A - supposes that the cause must be prior, or at least simultaneous with, the effect (Born, 1949).

The findings of relativity and quantum mechanics, however, have forced physicists to abandon this assumption, whereas it remains valid at the level of human experiences (Sowa, 2000), as seen in the organization sciences. For our model it is important to underline this epistemological gap between physics and the social sciences, as our approach is characterized by an interdisciplinary perspective integrating also the results of natural science research. The evolutionary perspective for this model represents the main catalyst for concepts of natural sciences (physics and biology). In this article we do not intend to figure out to which degree biology and humanities are able to integrate the discoveries of relativity and quantum mechanics, nor address the normative question related to which degree biology and social sciences should integrate findings of contemporary physics. Our approach is pragmatic and intends only to analyse the process in a way which allows for the most realistic interdisciplinary research on the innovation-ethic relationship. 
We believe that the most pragmatic and realistic construction of an innovation-ethic link model must involve the combination of the two seemingly disparate perspectives of behaviour, making these theoretical reflections necessary. Thus, it is important to document the epistemological background and prudent claims of this analysis and also to stress that a pragmatic approach cannot be identified with epistemological ignorance or a naïve understanding. Before continuing on to describe our model, we must emphasize three additional points from this epistemology:

I. Even if contemporary physics relativizes the causality concept, and even though our model includes the perspective of physics, the authors of this article analyse the innovation-ethic links by using the causality concept. We share Sowa's (2000) position that causality remains valid at the level of human experience.

2. The combination of the perspectives of natural and social sciences practiced in this model implies that the analysis of the process factors encompasses both types of factors: a) the factors acting independently from human awareness and decision-making, which reflect the "objective dimension" of the process and, b) the factors linked to human awareness and perception which trigger decisions and actions (Kahneman and Tversky, 1982), which represent the "subjective dimension" of the innovation-ethic link. The model tries to coherently link both dimensions, avoiding the traps of subjectivism and objectivism. This objective/subjective approach is important in this model for addressing the central notion of the time dimension.

3. The innovation-ethic relationship is not conceived as a mechanical or deterministic one. The model works with probabilistic causation. Even if such a cause has been revealed to be a central matter of fact in physical reality and has been largely accepted as a explanatory concept in social sciences, this feature of the model needs to be highlighted here, insofar as the model integrates a biological perspective.

Employing the (probabilistic) causality concept permits us to be able to analyse the innovation-ethic relationship from a process perspective and to integrate, at the same time, the duality concept. In this regard, we distinguish among the three classifications of causal factors (Epp, 2004):

A sufficient cause $\mathrm{X}$ is given, if its presence necessarily implies the presence of the effect $\mathrm{Y}$.

A necessary cause $\mathrm{X}$ is given, if the event $\mathrm{Y}$ cannot happen without $\mathrm{X}$, but the presence of $\mathrm{X}$ will not trigger that $\mathrm{Y}$ occur.

A contributory cause $\mathrm{X}$ may contribute to the occurrence of $\mathrm{Y}$, but not necessarily.

For the purpose of our analysis we have to add a fourth category of factors, which are not causal factors in a narrow sense, as they are not directly involved in whether something happens or exists, but they influence the intensity of an event or the speed of its occurrence. One can call them "intensifying/moderating factors" and "decelerating/accelerating factors". Moderation is already a well-known theory in the behavioural sciences for refining and more fully comprehending a causal relationship (Wu and Zumbo, 2008). Moderating factors are useful 
in explaining a more dynamic bivariate cause-and-effect relation, and "what alters the magnitude or direction of the causal relationship" (368).

\section{Some general consequences for the model}

\section{Long-term orientation}

As shown in the preceding sections, the long-term orientation of a firm can be grounded in the findings of natural science (specifically, evolutionary theory) with the underlying survival goal as well as in the social science literature, where socio-economic and operational research reveals the existence of functional imperatives, which reflect longterm orientated organizational survival necessities (Fusari, 2004; Parsons, 1987). We stress that despite the fact that our discussion focuses on the existence of tendencies, orientations, objectives or dispositions, it is not meant to imply a deterministic perspective, which would argue that in reality all these purposive potentials will be realized. Indeed, in the real world there are many obstacles sometimes prohibiting their realization, at least in the short-term. However, using these obstacles as proof of the non-existence of these tendencies is logically improper. So we will take the longterm orientation of an organization, reformulated as the firm's survival goal as the starting point of our Integrated Causal Model.

\section{Objectivity/Subjectivity and the dimension of time}

As mentioned earlier, natural science and social science let us face both the objective and the subjective dimensions of reality. In order to provide a coherent structuring of the different scientific perspectives of our interdisciplinary model, it is necessary to specify the objectivity/subjectivity issue. It is important to emphasize that subjectivity, linked to the character of human nature, is not limited to the interior of a single person, but is shared by group of persons. A shared form of subjectivity is transformed from a personal kind ("pure" subjectivity) to an interpersonal kind, called "inter-subjectivity". This "inter-subjectivity" provides the form of "objectivity" which is possible with human beings and the scientific reference for social sciences. For the comprehension of the ICM we use the term

"objective dimension" for the designation of facts independent from human awareness and decision. In other words, what is objectivity in the natural sciences is not necessarily objectivity in the social sciences. In the subjective dimension, however, there exists a nuance between a pure, personal subjectivity and inter-subjectivity, which is present in all social processes and organizations.

This clarification helps to define the central role of time in our model. Of course, time is a human notion and one of the dimensions that allows man to perceive the world. So time clearly belongs to the subjective dimension. However, we must be cognizant of the fact that our ICM encompasses at least two time perceptions: the time perceptions and concepts of the researchers-the "observers"---and the time perceptions of the observed decision makers. As for the prognostication of future trends in financial markets, it is not sufficient for scholars to know the duration of economic and political processes. They must also pay attention to the time horizon of the financial decision makers themselves who actually perceive and interpret these processes. In our case it is 
understandable that a scientifically observed long-term orientation of organizations can be challenged by a short-term orientation of the decision makers of the same organization.

The duality principle and causality

Following Farjoun (2010), the duality approach will be used in this model as one of its structuring elements. The duality perspective permits us to discover that (long-term) stability and change are not only compatible, but even linked in certain situations. By the same token, duality allows us to consider Fusari's (2004) notion that choice and duration are compatible, as it is the case with necessity and change. Ethical values and rules are normally associated with duration, stability and necessity, whereas innovation implies choice and change. So a duality perspective not only allows us to use insights from both the natural and social sciences, but also helps us demonstrate that organizational innovation and long-term stability are linked, as ethic and innovation forms a potential nonantonymic pair of survival tools. We combine the causality and duality perspectives in our model by using the causal perspective (described above) as a general framework (Figure I) in which the duality approach serves to highlight the principal bifurcation possibility concerning innovation and ethic (Figure 2).

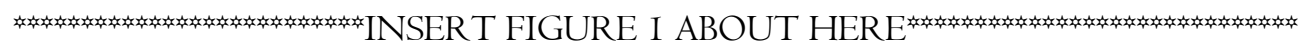

\section{The ICM of Moral Innovation Decision Processes}

\section{The causal link between survival objective and ethical innovation}

\section{Stage I}

In practice we have in mind the time horizon as declared by a firm's board of directors. The time horizon is presented with two poles (exclusively short and long-term). This represents a simplification for model purposes, but future research could investigate how the real "mix" of the perception of the time horizon develops inside the minds of a board of directors, by taking into consideration all the moderating factors mentioned above in Figure I. These intervening variables: average life span of a company, personal and cognitive factors, type of industry/profession, natural culture, and type of corporation in terms of structure and culture are all expected to influence Stage I. It should be noted that a detailed discussion of these potentially moderating variables is beyond the scope of the present article. Our intention is to identify these factors for the sole purpose of setting up possible future research of our model and its proposed relationships.

In order to understand the potential link between Stage I and Stage II, we outline some situations when decision makers in the firm may have an exclusively, or at least a dominant, short-term time horizon despite the longterm survival goal. Moral hazard in agency-type arrangements is a common organizational phenomenon (Eisenhardt, 1989). Related to this agency problem between the principal owner and decision making manager, is the latter party's propensity to abuse his/her power in the company. Power-seeking by individuals in organizations mitigates a corporation's ability to economize. The aggrandizement of power often is seen as the factor for the corporate scandals so commonly seen today (Frederick, 1995). Executives at Enron, WorldCom, and Goldman Sachs certainly 
had a greater interest in their own "short-term" selfish rewards than that of the "long-term" going concern of their respective companies. Frederick (1995) claims that power-aggrandizing values are another dominant natural value cluster that competes with individual's natural drive for organization.

The perceived time horizon of the decision makers may be of a short-term nature for other reasons though. It is feasible that the decision makers are aware of the survival goal, but feel pressured by the business environment to opt for the short-term horizon, being conscious that this implies a real risk for the survival goal. The pursuit of the goal is "deferred" to a later period. Here we can distinguish two subsets of this scenario, where a) the long-term reflection is deferred to later and applied in the following period or, b) where the same reflection is also deferred to a later period but not applied in the following period. Another scenario involves a situation when decision makers are aware of the survival goal but consider a predominantly short time horizon approach in pursuit of the long-term objectives. They think that the short-term goals are compatible with, or even a logical translation of, the survival goal. Thus it is necessary but not sufficient for principals of the organization to set a long-term objective for the company in order for this to be realized by the managerial decision makers.

These different scenarios with an immediate focus will occur with a particular probability depending on a large number of variables which affect the decision maker's perceptions and motivations in a certain context. Situational, environmental, and contextual factors are mentioned above and are identified in Figure I. These contributory variables are beyond the scope of our argument in this present paper, but should be addressed by future research related to our model.

Institutionalizing the long-term survival objective is necessary for the translation process to progress to a strong degree of ethical sensitivity in Stage II of the model. The formation of institutions in organizations creates functional expectations of all its members (Brunsson, 2002). Through collectively shared scripts, symbols, and assumptions of behaviour, organizations obtain cognitive-cultural constructions of reality (Suddaby et al., 2010). "Modern organizations themselves thus reflect the intensive cultural rationalization of the contemporary world in their constitutive structures" (I234). For organizations to institutionalize the long-term perspective involves attributing meaning and significance of survival to all normal processes and decisions. For example, 3M, the innovative company who develops technical solutions to a variety of manufacturing problems, is entrenched in a culture of innovation for long-range challenges. The principals of $3 \mathrm{M}$ allocate $\mathrm{I} 5$ percent of each of their research employee's time to seeking out their own ideas (Herr, 2010). That is, 3M's culture encourages the development of long-range solutions; not short-term quick fixes. Creativity and idea generation have become institutionalized in the company through the nurturing of a non-bureaucratic organizational structure, and the formation of a strong culture rooted in their innovative social identity.

We have identified two extremes in the vision of the time dimension for decision makers. Those organizations with a short-term focus (for whatever reason) are more likely to have only developed a weak ethical 
sensitivity, while those with an institutionalized long-range objective are more likely to have a strong ethical sensitivity in Stage II of our model.

$\underline{\text { Stage II }}$

At this stage, we refer to "ethical sensitivity" as the degree to which ethical values are engrained in the minds of the corporate decision makers in a particular business organization. Conceptually, we believe there is a direct relationship between a managers' predominant time dimension focus for their work within an organization, and their predominant value set. It is widely accepted in the organizational behaviour and business ethics literature that CEO values vary greatly from person to person (Hambrick and Mason, 1984), and that the variation can be partially attributed to organizational culture (Frederick and Weber, 1987; Sen, 1997). (Of course there are individual factors relevant to the formation of an individual's ethical sensitivity as well, but due to the scope of the present article, a discussion of those influences related to the model must be left for future research.) "Organizational cultures can have many functional effects on organizations and their management" (Champoux, 2008: 76). Through the culture of the organization, values are communicated to and adopted by the members of the firm. This is one element of the institutionalization process described by the social sciences force. One key dimension of values regards the degree to which an individual is self-interested or other-regarding. Organizational cultures that place emphasis on the ethical treatment of multiple stakeholder groups of the organization, and not just on personal gain can nurture otherregarding values in the corporate executive (Agle, Mitchell, and Sonnenfeld, 1999). On the other hand, cultures that emphasize short-term goals are more likely to nurture self-interested value clusters (Dawkins, 1987). Once again this has implications for agency theory. Moral hazard can result from self-interested individuals operating for their own short-term gain (Jensen and Meckling, 1976). Other-regarding individuals are more likely to be focused on maintaining long-term relationships with stakeholders of the firm. These individuals value decisions that balance the needs of multiple groups; thereby respecting their rights.

Human culture is a partial expression of the natural forces we have been discussing in this stage. "This evolutionary embeddedness of culture has played a central role in bringing forward the core value components of business, for culture is only another manifestation of the regularity and patterning that accompany the operation of thermodynamic laws" (Frederick, 1995: 83). Culture makes it possible for a diverse set of economizing and technosymbolic value sets.

In our model (Figure I), we must avoid misleading, overgeneralized conclusions and understand that a weak ethical sensitivity towards others is not automatically the result of unawareness with regard to the survival goal, even if awareness of the survival necessity reinforces the degree of ethical mindfulness. In other words, a short-term time horizon does not necessarily lead to weak ethical mindfulness. Short-term goals can indeed include an ethical sensitivity for "others." However, a short-term focus is not a sufficient condition for the translation process to progress to this stage. A long-term focus is indeed a necessary and essential contributory element for the progression. Ethical sensitivity seems to us to be an important stage on the causal path from the time horizon focus of corporate 
decision makers and the institutionalization of the ethical values tied to the survival goal into the value system of the firm.

$\underline{\text { Stage III }}$

The third stage of our proposed model involves three steps that lead to the type of business model adopted by the firm. It is at this stage that institutionalization of the ethical values associated with the long-term survival goal takes form. Step I involves the integration of the long-term survival vision into the company's values system. The "otherregarding" values dimension from Stage II is legitimized in this first step through the establishment of values statements or codes of conduct, ethics training, and the socialization process (Fisher, 1986). Thus this first step involves the development of normative rules for decision-making in the organization. The role of normative institutions for establishing a corporate social responsibility agenda is profound (Blasco and Zolner, 20I0). For instance, for a CSR business model to be established, there must be a clear, deeply embedded values system in place that considers social responsibility a mandate, and not only an instrumental tool for making short-run profits.

Once the values are clearly articulated and accepted throughout the organization, the second step of this stage in our model involves establishing coherent and realizable goals for the organization. Goal-setting theory (O'Leary-Kelly, Martocchio, and Frink, 1994) is a behavioural theory of motivation. The values that are espoused by the members of the organization must be translated into specific, concrete goals. The intricacies of goal setting theory are omitted here due to scope, but that should not minimize the importance of this step in the translation process. Setting goals involves several steps including the specification of the time dimension of the organizational goals (Locke and Latham, 1990). After the goals are determined formally, organizational members engage in the strategic decision-making process.

In Step 3 of this stage, there is the translation of the normative values system into the company's strategic decisions. At two extremes, a company can either make strategic decisions based on short-term profit maximization, or for a long-term going concern. These two types of business model, or vision of the organization, exist on a continuum. So once again it is expected that short-term, economizing decisions be integrated into decisions affecting the long-term success of the firm. Organizations define success based on whether a process assists in the realization of the company's goals set. Rules are only institutionalized if they lead to success, or survival. Hence, there is an implied feedback mechanism in effect within our model. Ethical rules "can only acquire normative force if action leads to success; once success is attained, rules with normative force can be formulated" (Peacock, 2010: 289).

$\underline{\text { Stage IV }}$

The new process that results combines innovation decisions with a consideration of ethics. This is the stage at which the innovation-ethic duality has been realized. The translation from principal goal to actual behaviour will become institutionalized if successful practices persist. "New practices, if they persist, will become routinised, and consequently they form the basis of new normative standards which justify the new practices" (Peacock, 2010: 289). Logically speaking, the new value system from Stage III will become legitimized when the practices are seen as 
successful. To finally reach this point in the model, the decision-maker must justify that the new normative rules are a necessary condition for the long-term survival of the organization. We discuss the duality in more detail next.

\section{Duality of Innovation and Ethic: A Typology}

Our Figure 2 is an adaptation of Fajoun's (2010) duality concept (presented earlier in this article) by the incorporation of the ethical dimension into the theory. We have created a typology along two axes: "Outcomes", and "Mechanisms". These are rather logical sorting criteria in that they are consistent with the ethical traditions of teleology and deontology (i.e., consequences and processes; or ends and means). On both dimensions, the typology is spit into Ethic and Innovation, and on each dimension, the social science forces as well as the natural science forces described in this paper are present. We make no attempt to distinguish between the forces at this stage, since we firmly believe both are influencing factors on the duality.

On the "Outcomes" axis, we define Ethic in terms of utility, where the ethic is related to predictability, regularity, and reliability of ethical outcomes. Here benefits and costs are paramount to the decision. The other end of the "Outcomes" axis describes the consequences of the Innovation. An innovation is evaluated on how adaptable and flexible it is to a turbulent environment; that is, how successful is the innovation at economizing. Along the other axis, the "Mechanisms" of Ethic and Innovation form the other decision criterion through which we evaluate the duality. Ethic on this axis is defined by moral rules, routines, and institutions defined by the organizational culture. The socialization processes discussed earlier are mechanisms for translating the principles into organizational identities and procedures. Codes of conduct and values statements are utilized to institutionalize certain moral values within the company. The "Mechanisms" for Innovation involve the techno-symbolic values and techniques for innovating. How a company achieves self-organizing structures for economizing imports another critical aspect of the ethic-innovation duality.

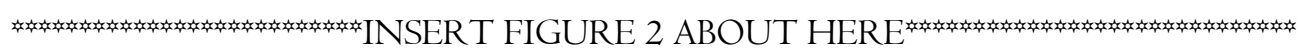

Figure 2 shows that ethic and innovation can be interdependent and mutually enabling (Quadrants II and III), but at the other extreme, when one or the other is ignored, the organization is likely to face obstacles to survival (Quadrants I and IV). Thus, the duality occurs at the intersection of Ethic and Innovation for "Outcomes" and "Mechanisms". In these situations, we see it likely that ethics will be embedded in innovation processes in organizations. Now we walk through the typology, briefly describing the resulting behaviour we would expect when certain elements of each decision criterion are present.

Quadrant I shows what happens if there exists an ethic without any attention and link to innovation. In this first case, the moral system risks becoming so rigid and inflexible that the sustainability of the moral system is seriously in danger. One would be face to a "fossilizing ethic". Here the strong ethical values of the company inhibit innovation and adaptability, thereby paralyzing change. Survival of the company is in jeopardy. The mechanisms for 
promoting the moral norms of this type of company do not permit room for change out of fear that the ethical values of the firm will be compromised. What appears to be morally stoic and well-intentioned is in actuality too rigid a system for realizing a long-term going concern. One example of this kind of restricting ethic involves codes of conduct. Very strict, overly detailed organizational codes of conduct are often criticized for inhibiting active processing, and by consequence creative thinking (Kapstein and Schwartz, 2008). These static types of codes are likely to be ineffective when stakeholders of the code follow the 'letter-of-the-law' because they discourage any kind of deviation from what the institutionalized norm tells them to do. There is no long-term time frame; each situation is analysed by the code in that present moment. There is a tendency with these companies to try to fit every situation into the specific rhetoric of the code. We posit that it in terms of innovation, the firm will suffer. Hence, innovation is a necessary element for the ethic to be realized in the long-term.

In Quadrant II, we find innovation—-perceived by the decision makers as long-term oriented— which helps a company to survive and to maintain its ethical code, or which-if they are of the value-innovation type (Fusari, 2004: 526)—permits them to set up a new moral value mix (i.e., an innovated ethic). Furthermore, moderate innovation in the ethical field limits the risk of externally driven change provoking a collapse or deterioration of the existing moral norms. So Quadrant II encompasses an ethic-innovation link which we designate as "Survival of ethic/ innovated ethic". This is our first duality in the typology. Regarding the natural sciences side of our argument, the natural values that guide and sustain life, drive individuals to innovate. Without the natural tendency to adapt to change, there is no long-term survival. The techno-symbolic values enable individuals to constantly find new ways to economize. Through economizing, individuals and organizations design temporary self-organized structures to promote survival. Innovation requires creativity, new ideas, diversity and cooperation. Decision-makers who realize the long-term time dimension must incorporate "other-regarding" values into their decision processes in order to integrate the collective interests of an organization. One who has a survival goal is likely to be more inclined to cooperate with others and understand the important of addressing the needs of multiple stakeholders of the organization. Thus, the long-term vision of the decision-maker enables an underlying ethic for the organization. Leaders with this perspective are more likely to be successful at institutionalizing ethics into the culture of the organization through the promotion of ethical values to a wide array of stakeholder groups.

The next cell, Quadrant III represents the other duality on our typology. The combination of an ethic mechanism with an innovation outcome-orientation in this cell illustrates firms who use ethical control mechanisms to enable (long-term) innovation. The institutionalization of ethics (by the means discussed in this article) facilitates economizing in the long-term. Survival goals are more likely to be realized by firms with these characteristics because ethical awareness helps them to legitimate long-term innovation. We refer to this quadrant as "Ethical innovation". The natural values that form the substrate of economizing and technologizing actually facilitate innovation. These are original business values in the sense that the underlying natural beliefs, relationships, and motivations are necessary conditions for businesses to "sustain steady-state economizing over the long-term 
(Frederick, 1995: 25). These natural values often favor other-regarding behaviours because cooperation and fairness are critical elements of a business with a going concern. For example, from the operations literature, Stoddard (2005) devised a model to assist the U.S. Minerals Management Service, a U.S. federal government agency, in maximizing natural gas royalties in the face of challenging logistics for the transport of the natural gas from the reserves to its destination. The focus of this model was only on innovation in the short-term. Plus there was no implicit ethic in the innovation process. The federal agency in this case would find themselves in Quadrant IV of our typology (discussed below) — a complete focus on short-term innovation to deal with an immediate problem. The complete foil of this innovation is an example from IBM. In an effort to address long-term survival goals, the company devised a model that examined product quality and customer interests (Kirkwood et al., 2005). In this case we see an organization that incorporated stakeholder interests into the development of their innovation. Their innovation was actually driven by an "other-regarding” concern for their customers. The former case involved only a self-interested value for optimizing profit.

In Quadrant IV one finds the opposite of Quadrant I. Quadrant IV shows what happens if innovation works without any attention to the ethical dimension. While the first cell (Quadrant I) inhibits innovation in the long-term through a too rigid short-term conception of ethics, this cell describes firms that are characterized by amoral innovation. This can happens due to the implementation of exclusively short-term oriented innovations where the consideration of the ethical dimension is, at least, "suspended." Given the exponentially fast rate of change facing most industries and professions around the globe today, managerial decision-makers have become accustomed to pressures to constantly change to respond to evolving marketplace demands. However, we posit that this pressure is often justified by the perceived need to expand and generate more short-term profit. Another possibility is that the innovation is used for purposes which are considered by the business environment as unethical. For example, some innovations could be used for the purposes of management to power aggrandize and track private information of their employees (perhaps without their knowledge) for short-term gain. In operations research, there is a concern that new models and innovations are developed without any regard for the consequences of the implementation of the OR model (Brans and Gallo, 2007). Those constituents of a certain operations innovation may have their human rights violated. Models in the past have been used to help banks accumulate more short-term profit by innovating ways customers would be charged not-sufficient funds fees even if they were equipped with overdraft protection (LeMenestral and VanWasserhove, 2004). This innovation decision was in clear violation of customers' rights to property, and the fairness/justice principle (Rawls, I999). A third possibility, would be for a company to claim that they are indeed respecting ethical concerns of the stakeholders by declaring that "innovation" itself is a unique moral value treasured by business and society. Following the established and shared conviction that a moral system is characterized by a combination of commonly held universal moral principles (or at least dictated by a particular culture, implying a relativistic ethic) and not by a unique one (Donaldson and Dunfee, I999), we would consider such an approach also as "unethical”. For these reasons, we label Quadrant IV as, "Unethical innovation”. 
We hope that by discussing this typology of behaviour in organizations, we open up possibilities for future research to empirically test relationships in our model. We offer a few of those suggestions in the final section.

\section{Discussion}

We began this theoretical article with the question: Is it in the best interest of companies to integrate an ethical dimension into their innovation processes? Our argument is that not only is it in a company's best interest for facilitating long-term survival, but also the ethical dimension is implicit in innovation efforts in organizations with a long-term time focus. In business, ethics are incorporated for the purpose of improving "the moral conduct of business" (Kaler, 2000: 264). This is not counterintuitive to long-term organizational survival goals. For management researchers and practitioners, looking at the ethical dimension should constitute an acknowledgement of the impacts the decisions business managers make on society, both in terms of desired effects, as well as a concern for the unforeseen consequences associated with the model's implementation (Drake, Gerde, and Wasieleski, 2008). It involves the realization that there are no value-neutral judgments in decision-making (Gallo, 2004). The constant improvement of organizational and social processes is not mutually exclusive to either innovation management or business ethics (Churchman, 1970; Singer and Singer, 1997).

Ethic does not sit in isolation from business processes. Rather, we have argued in this article that there is a normative dimension implicit in business practices, and individual managerial behaviour. When discussions on business processes are kept independent of discourses on ethic, there is a natural tendency to connect the two (Freeman, 1994). Accepting the separation thesis is dangerous in that morally neutral theories and models can result, "which can be used to justify a great deal of harm" (Freeman, 1994: 4I2), or that focus too much on shortterm effects of decisions (Velasquez, 2005). Logically speaking, an "other-regarding," stakeholder view of the organization implies that the discourse of business processes and decision-making and ethic are intertwined. We feel in this paper that one of our main contributions is to embed a discussion of the ethical dimension well within the development of an innovation process with a long-term focus.

A concern for stakeholder needs beyond those of just the shareholder group has become a major factor in corporate governance and strategic management decisions (Clarke, 1998). These stakeholder interests are valueladen and go beyond a firm's immediate focus on short-term profit-making. Around the world, managers are being forced to align strategies and values that will lead to more socially responsible decision-making in the long-term. In fact, firms now realize that paying attention to long-range social and environmental concerns "are critical to the business agenda" (Clarke, 2007: 79). This transition of corporate interests took place at the end of the last millennium. Unfortunately, to date the innovation literature has not indicated an evolution of this idea from corporate governance that this aligning is facilitated by having a concern for moral rules in developing innovation processes. We believe our paper has made a contribution in this regard. 
Potentially, our model could hold significance as a contribution towards a paradigmatic shift in the understanding of how innovation processes actually work, and how the ethical dimension is viewed in innovation and change research. Thomas Kuhn defines a paradigm as "a model from which springs particular coherent traditions of scientific research" (Kuhn, I962: I0). The paradigm theory has two main characteristics: it is "sufficiently unprecedented to attract an enduring group of adherents away from competing modes of scientific activity" (I0), and it is obtuse in that it allows for further work to be conducted and specific problems to be solved. He posits that a field with a paradigm is a sign of maturity for that area, although research can indeed be conducted without one. In fact, pre-paradigm research is part of what he calls normal science, or "research firmly based upon one or more past scientific achievements..." that for a time supply "the foundations for its further practice" (I0).

Kuhn outlines the steps of normal science en route to paradigm development. Although he illustrates the process using natural science examples, normal science can easily be applied to the social sciences as well. As a starting point, scholars in a particular field share a perceived truth of the world. This truth serves as the basis for understanding phenomena in a discipline. It is a belief or theory that shapes the perception of the mechanics of behaviour. In our paper, we identify two perceived truths—stability and change from a natural sciences perspective, and also from a social science perspective. However, as a truth continues to be applied to various circumstances and contexts, questions regarding its validity begin to become salient to the scholars in the field. Like Farjoun (2010), we have questioned the validity of the dualism of the two fields.

Then suddenly, after numerous applications, the truth proves fallible to certain types of generalizations. Hence, doubts are raised in the minds of the scholars of a certain field. The doubt stage of normal science is characterized by an awareness that the perceived truth does not function in all cases. We have shown those cases in our typology from the previous section. Agents of the field question its usefulness following observing phenomenon when the truth does not remain undistorted. In the innovation literature, it is currently recognized that there is definitely an emphasis on "limited, short-term engagement that limits social responsibility" and ethic (Midttun, 2010). We hope we have directed research towards more long-range thinking. Here we see there being real possibilities for future research on ethics and innovation. There are opportunities to empirically testing aspects of our model to determine whether indeed a combination of the natural values and cultural, socially constructed values do indeed lead to an innovation-ethic duality in organizations. We believe we have laid the groundwork for a newly conceived subfield based on the integration of the natural and social sciences to address the ethic of innovation in turbulent environments.

Our contributions are not limited to theoretical development. There are potential implications for management if our model empirically proves to be robust. If managers in organizations are aware of the natural tendencies of individuals, and understand the natural processes that govern survival at the individual and organizational levels of analysis, then perhaps new systems can be designed that work with these inescapable natural forces to enable long-term survival. If BP decision-makers did not focus as much on the short-term profit motive, 
and instead took a long range view of the organization's role as a corporate citizen, responsible to numerous stakeholder interests, then perhaps some shortcuts in the technical and quality-control processes may not have been taken and the environmental disaster could have been avoided. Corporate decision-makers should also take these insights from our model and proposed typology, and recognize the importance of institutionalizing ethical values in their organizations. It is possible that the notions described in our framework can generate change across firms if a couple of key firms within an industry champion the idea of ethical innovation for long-term survival. When faced with institutional pressure to change, Sony created a corporate governance innovation in the late 1990s. The new processes they adopted provided effective mechanisms for monitoring the needs of stakeholders external to the organization. "Sony's corporate governance innovation is the distinguishing event in the field, and its innovation has spread across firms" (Yoshikawa, Tsui-Auch, and McGuire, 2007: 979). Ethic enables long-term innovation.

\section{Potential Future Research}

Figure I reveals a large field of potential future research. Linked to Stage I, we identify several potential moderating variables of the perceived time horizon of the decision-makers. Researchers in operations and innovation management should examine the cognitive factors of the decision maker that may act as antecedents of a person's time horizon focus. Are their heuristics from cognitive psychology that bias an individual to take a particular time perspective for the firm? To date, little interdisciplinary work has been done between cognitive psychology and innovation. Business ethics and corporate governance research could also investigate the influence of the personal factors on the process of the collective development of a shared time-horizon in the organization.

Another potential investigation path is the examination of the role the type of business sectors has on perceived time horizons and ethical sensitivity. Ethicists can examine the particular professions and industries with long-term affinities and those sectors with a strong or weak ethical sensitivity. Whatever the findings would have implications for corporate governance research across the sectors. One can imagine that taxonomies of economic sectors could be established specifying the corresponding types of time-horizons and corresponding degrees of ethical sensitivity. This research would reveal the type of obstacles for the development of a long-term time horizon and/or of a strong ethical sensitivity. These findings could then lead to an investigation into the proper strategies even in an institutionalized form - needed to remove these obstacles. It follows that the actual type of organization, in terms of ethical work climate and culture, and also in terms of how the organization is structured may influence the time horizon and ethical sensitivity of the decision-makers. Research on organizational influences on individual's cognitive decision-making should be expanded to include the perceptions of time dimension of the firm.

Future research should also examine the sociological and cultural factors, which we outlined in the examination of Fusari's Grand Options that could act as a moderator of the first two stages of the model. It seems to us extremely promising, facing the globalised business world of today, to inquire about the degree to which national 
culture influences the time horizon and the ethical sensitivity of corporate decision makers. This inquiry could also be made cross-culturally in a comparative analysis.

There is also an opportunity to empirically study the comparative success of the two types of business model we offer in Stage III of our framework. Data on corporate financial and social performance is available through Bloomberg data services and the KLD database, respectively. Future research should examine whether indicators of a weak ethical sensitivity correlate with a short-term, profit-maximization model, and whether or not indicators of strong ethical sensitivity predict a certain level of corporate social responsibility. Furthermore, the causal link between a CSR-type business model and the innovation-ethic duality should be explored.

In conclusion, we hope our proposed model and typology has expanded readers' minds to think about innovation decisions in a different way. Our Innovation-Ethic Duality Model is unique in that it demonstrates the strategic role moral rules can have on the change process in organizations, and how long-term innovation decisions can mandate the need for an institutionalization of an ethic. Moreover, we were able to reach this conclusion only by integrating natural science and social science assumptions and theories. By offering our Integrated Causal Model, we feel we have painted a more realistic portrait of how a company's survival interest can be translated into ethical innovation. Since our model is new and in part designed in response to a call by the ethics field to incorporate an ethical dimension into innovation decisions, we see this article as an important first step. We see our proposed framework as a springboard for much exciting future research in the field.

\section{References}

Abernathy, W. J.: 1978, The Productivity Dilemma (J. Hopkins Press, Baltimore).

Agle, B.R., R.K. Mitchell, and J.A. Sonnenfeld: 1999, 'Who Matters to CEOs? An Investigation of Stakeholder Attributes and Salience, Corporate Performance, and CEO Values', Academy of Management Journal 42(5), 507525.

Almirall, E. and Casadesus

Masanell, R.: 2010, 'Open Versus Closed Innovation: A Model of Discovery and Divergence', Academy of Manage ment Review 35, 27-47.

Aristotle: 2006, Metaphysics (translated by W.D.Ross) (Digireads, Stilwell, KS).

Baskin, K.: 1998, Corporate DNA: Learning from Life. (Butterwork-Heinemann, New York).

Baucus, M.S., Norton Jr., W.I., Baucus, D.A., and Human, S.E.: 2008, 'Fostering creativity and innovation without encouraging unethical behaviour', Journal of Business Ethics, 8I, 97-I I5.

Blackmore, S.: 1999, The Meme Machine (Oxford University Press, Oxford, England).

Blasco, M. and M. Zolner: 2010, 'Corporate Social Responsibility in Mexico and France: Exploring the Role of Normative Institutions', Business and Society 49(2), 216-25I.

Bloomer, A., K. Jagoda, and J. Landry: 2010, 'Canadian Oil Sands: How Innovation and Advanced Technologies Can Support Sustainable Development', International Journal of Technology Management and Sustainable Development 9(2), II3-I32. 
Bonner, S. E.: 1990, 'Experience Effects in Auditing: The Role of Task-Specific Knowledge', The Accounting Review 65 (January), 72-92.

Born, M.: 1949, Natural Philosophy of Cause and Chance (Dover Publications, New York).

Boudreau, K. J.: 2006, 'How Open Should an Open System Be? Essays on Mobile Computing', Submitted to the Sloan School of Management in partial fulfillment of the requirements for the degree of Doctor of Philosophy, Massachusetts Institute of Technology.

Brans, J-P. and Gallo, G.: 2007, 'Ethics in OR/MS: Past, Present and Future', Annals of Operations Research I53, I65-I78.

Brunsson, N.: 2002, The Organization of Hypocrisy (2 ${ }^{\text {nd }}$ edition) (Abstract, Oslo, Norway).

Carlsson, B.: 2006, 'Internationalization of Innovation Systems: A Survey of the Literature', Research Policy 35(I), 56-67.

Carlson, D.S., and P.L. Perrewe: 1995, 'Institutionalization of Organizational Ethics Through Transformational Leadership', Journal of Business Ethics I4, 829-838.

Chambers, R.: 1844, Vestiges of the Natural History of Creation (John Churchill, London).

Champoux, J.E.: 20I I, Organizational Behaviour: Integrating Individuals, Groups and Organizations, $4^{\text {th }}$ edition (Routledge, New York).

Chesbrough, Henry W.: 2003, 'The Era of Open Innovation', MIT Sloan Management

Review Spring, Reprint 4435, 35-4I.

Chesbrough, H., W. Vanhaverbeke, J. West (eds.): 2006, Open Innovation:

Researching a New Paradigm. (Oxford University Press, Oxford, England).

Churchman, C. W.: 1970, 'Operations Research as a Profession', Management Science Vol. I7, No. 2, Application Series, Educational Issues in the Management Sciences and Operational Research (Oct.), pp. B37-B53.

Clarke, T.: 1998, 'The Stakeholder Corporation: A Business Philosophy for the Information Age', Long Range Planning 3I(2), I82-I94.

Clarke, T.: 2007, 'The Evolution of Directors Duties: Bridging the Divide Between Corporate Governance and Corporate Social Responsibility', Journal of General Management 32(3), 79-I05.

Cosmides, L., and Tooby, J:: 2000b, 'The Cognitive Neuroscience of Social Reasoning', In M.S. Gazzaniga (Ed.), The Cognitive Neurosciences (2nd.Ed.) MIT Press, Cambridge, MA), pp. I259-I270.

Cosmides, L., Tooby, J.: 2004, 'Social Exchange: The Evolutionary Design of a Neurocognitive System', In Gazzaniga, M.S. (Ed.), The Cognitive Neurosciences, vol. III. (Bradford Books, New York).

Coveney, P. and C. Highfield: 1990, The Arrow of Time (Fawcett, New York).

Darwin, C.: 1859, The Origin of Species (I958 Edition), (New American Library, New York). 
Dawkins, R.: 1987, The Blind Watchmaker (W.W. Norton and Company, New York).

DeGeorge, R.: 2008, 'An American Perspective on Corporate Social Responsibility and the Tenuous Relevance of Jacques Derrida', Business Ethics: A European Perspective 17(1), 74-86.

Deming, W. E.: 1986, Out of the Crisis (MIT Press, Cambridge, MA).

Dennett, D.C.: 1995, Darwin's Dangerous Idea: Evolution and the Meanings of Life. (Touchstone, New York).

Derry, R., T.L. Fort, W.C. Frederick, and N.R. Hauserman: 1999, Nature's Place in Legal and Ethical Reasoning: An Interactive Commentary', American Business Law Journal 36 (4), 633-670.

Di Norcia, V.: 1994, 'Ethics, technology development, and innovation', Business Ethics Quarterly 4(3), 235-252.

Donaldson, T., and T.W. Dunfee: 1999. Ties That Bind(Harvard Business School Press, Boston).

Durkheim, E.: 1967, De la division du travail social (I893), (Presses Universitaires de France (PUF) Paris).

Eisenhardt, K.: 1989, 'Agency Theory: An Assessment and Review', Academy of Management Review I4(I), 57-74.

Elias, N.: I99I, The Society of Individuals (Blackwell, Oxford, England).

Epp, S.: 2004, Discrete Mathematics with Applications, $3^{\text {rd }}$ edition (Brooks/Cole-Thomson Learning, New York).

Farjoun, M.: 2010, 'Beyond Dualism: Stability and Change as a Duality', Academy of Management Review 35(2), $202-225$.

Fassin, Y.: 2000, 'Innovation and Ethics: Ethical Considerations in the Innovation Business', Journal of Business Ethics 27, 193-203.

Follett, M. P.: 1924, Creative Experience (Thoemmes, Bristol, U.K.).

Frederick, W.C.: 1995, Values, Nature, and Culture in the American Corporation. (Oxford University Press, New York).

Frederick, W.C.: 2004, 'The Evolutionary Firm and Its Moral (dis)contents. In R. Edward Freeman and Patricia H. Werhane (Eds.) Business, Science, and Ethics, The Ruffin Lecture Series 4. Charlottesville, VA: Society for Business Ethics, pp. I45-176.

Frederick, W.C. and J. Weber: 1987, 'The Values of Corporate Managers and Their Critics: An Empirical Description and Normative Implications', In W.C. Frederick and L. Preston (Eds.) Research in Corporate Social Performance and Policy (JAI Press, Greenwich, CT), pp. I3I-I52.

Freeman, R. E.: 1994, 'The Politics of Stakeholder Theory: Some Future Directions'

Business Ethics Quarterly 4: 409-42I.

Freeman, R.E. and J.D. Harris: 2009, 'Creating Ties That Bind', Journal of Business Ethics 88, 685-692.

Fusari, A.: 2004, 'A Reconsideration on the Method of Economic and Social Sciences: Procedure, Rules, Classifications', International Journal of Social Economics 3I(5/6), 50I-535. 
Gallo, G.: 2004, 'Operations Research and Ethics: Responsibility, Sharing and Cooperation', European Journal of Operational Research I53, 468-476.

Gehani, R.R., and Gehani, R.: 2007, 'Mary Parker Follett's Constructive Conflict: A 'Psychological Foundation of Business Administration' for Innovative Global Enterprises', International Journal of Public Administration 30, 387404.

Giddens, A.: 1984, The Constitution of Society: Outline of a Theory of Structuration (Polity Press, Cambridge, England).

Goodpaster, K.: I99I, 'Business Ethics and Stakeholder Analysis', Business Ethics Quarterly I(I): 55-73.

Griffin, J. and J.F. Mahon: 1997, 'The Corporate Social Performance and Corporate Financial Performance Debate. Twenty-Five Years of Incomparable Research', Business Society 36(I), 5-3I.

Grönlund, J, D. Rönnberg Sjödin, and J. Frishammar: 20I0, 'Open Innovation and the Stage-Gate Process: A Revised Model for New Product Development', California Management Review 52, I06-I32.

Hambrick, D.C. and P.A. Mason: 1984, 'Upper Echelons: The Organization as a Reflection of its Top Managers', Academy of Management Review 9(2), 193-206.

Herr, P.: 2009, Primal Management. (American Management Association, New York).

Hoxie, R.F.: I9I5, Scientific Management and Labor, (D. Appleton and Company, New York).

Hull, D. L.: 2002, 'Species, Languages and the Comparative Method', Selection 3 (I), I7-28.

Jacobsson, S. and A. Bergek: 2004, 'Transforming the energy sector: the evolution of technological systems in renewable energy technology', Industrial and Corporate

Change, I3(5), 8I5-849.

Janssen, O., E. Van De Vliert and M. West: 2004, 'The Bright and Dark Sides of Individual and Group Innovation: a Special Issue Introduction', Journal of Organizational Behaviour 25(2), I29-I45.

Jensen, M.C. and W.H. Meckling: 1976, 'Theory of the Firm: Managerial Behaviour, Agency Costs, and Capital Structure', Journal of Financial Economics 3, 305-360.

Kahneman D. and A. Tversky: I982, 'The Psychology of Preferences', Scientific American 246, I60-I73.

Kaler, J.: 2000, "Positioning Business Ethics in Relation to Management and Political Philosophy”, Journal of Business Ethics, 24, 257-272.

Kant, I.: 1784, Idee zu einer allgemeinen Geschichte in weltbürgerlicher Absicht, In Kant, Immanuel, Werke, Akademie Textausgabe: Akademie-Textausgabe. Bd.8, Abhandlungen nach I78I, Gruyter September I, I97I, Berlin, New York.

Kant I.: I783, Prolegomena zu einer jeden künftigen Metaphysik, die als Wissenschaft wird auftreten Können (Friedrich Hartknoch, Riga, Lithuania).

Kirkwood, C.W., M.P. Slaven, and A. Maltz: 2005, 'Improving Supply-Chain Reconfiguration Decisions at IBM', Interfaces 35, 460-473. 
Kuhn,T. S.: 1962, The Structure of Scientific Revolutions (University of Chicago Press, Chicago, IL)

Le Menestrel, M. and L.N. Van Wassenhove: 2004, 'Ethics Outside, Within, or Beyond OR Models?', European Journal of Operational Research 153, 477-484.

Locke, E.A., and G.P. Latham: 1994, 'Goal Setting Theory', In Motivation: Theory and Research (H.F. O'Neil and M. Drillings, Eds.) (Lawrence Erlbaum Publishers, Hillsdale, NJ), pp. I-29.

Luhman, N.: 1996, Social Systems (Stanford University Press, Stanford, CA).

Malinowski, B.: 200I, A Scientific Theory of Culture and Other Essays (1944) (Routledge, New York).

March, J.G.: I99I, 'Exploration and Exploitation in Organizational Learning', Organization Science 2, 7 I-87.

Midttun, A.: 20I0, 'Corporate Social Responsibility From a Resource and Knowledge Perspective', Corporate Governance 7(4), 40I-4I3.

Munir, K.A.: 2005, 'The Social Construction of Events', Organization Studies 26(I), 93-I04.

O'Leary-Kelly, A.M., J.J. Martocchio, and D. D. Frink: 1994, 'A Review of the Influence of Group Goals on Group Performance', Academy of Management Journal 37: I285-I30I.

Pareto, V.: 197I, Manual of Political Economy (Augustus M. Kelley, London).

Pareto, V.: 1902 [1982], 'Di un nuovo errore nello interpretare le teorie dell'economia matematica', Giornale degli Economisti, I2(I5): 40I-33, reprinted in Ouvres Completes 26: Écrites d'économie politique, edited by Giovanni Busino, Genéve: Librairie Droz, 1982: 488-520.

Parsons, T.: I95I, The Social System (Routledge, New York).

Parsons, T. and N.J. Smelser: 1970, Economy and Society, A Study in the Integration of Economic and Social Theory (Routledge, New York).

Pavelin, S., and L.A. Porter: 2008, 'The Corporate Social Performance Content of Innovation in the U.K.', Journal of Business Ethics 80, 7I I-725.

Peacock, M.: 2010, 'Institutional Normativity and the Evolution of Morals: A Behavioural Approach to Ethics', Journal of Business Ethics 95, 283-296.

Petzinger, T.: 1999, The New Pioneers (Simon and Schuster, New York).

Pierce, B. D., and R.E. White: I999, 'The Evolution of Social Structure: Why Biology Matters', Academy of Management Review 24, 843-853.

Pfeffer, J.: 1997, New Directions for Organization Theory Problems and Prospects (Oxford University Press, New York).

Rawls, J.: I999, Theory of Justice (Belknap Press, Cambridge, MA).

Rich, A.: 1984, Wirtschaftsethik, It edition (Gerhard Mohn, Gütersloh). 
Rokeach, M.: 1973, The Nature of Human Values (Free Press, New York).

Roman, R. M., S. Hayibor, and B.R. Agle, B. R.: I999, 'The Relationship Between Financial and Social Performance: Repainting a Portrait', Business and Society 8(2), I44-I68.

Ruth, M.: 1993, Integrating Economics, Ecology and Thermodynamics. (Kluwer Academic Publishers, Dordrecht, The Netherlands).

Schein, E.: 1985, Organizational Culture and Leadership (Jossey-Bass, San Francisco).

Schumacher, E. G.: 1985, Grundprobleme der Entstehung von Selbsthilfeorganizationen in Entwicklungsländern (Duncker and Humblot, Berlin).

Seibel, H.D.: 1980, Struktur und Entwicklung der Gesellschaft (Kohlhammer, Stuttgart, Berlin, Cologne).

Sen, A.K.: 1997, Resources, Values, and Development (Harvard University Press, Cambridge, MA).

Sinclair, A.: 1993, 'Approaches to organisational culture and ethics', Journal of Business Ethics I2(I), 63-73.

Singer, M. S. and A.E. Singer: 1997, 'Observer Judgments about Moral Agents' Ethical

Decisions: The Role of Justice and Moral Intensity', Journal of Business Ethics 16, 473- 484.

Smith, H.: I991, The World's Religions, (Harper, San Francisco).

Sowa, J. F.: 2000 Knowledge Representation: Logical, Philosophical, and Computational Foundations

(Brooks/Cole, Pacific Grove, CA).

Stoddard, S.A.: 2005, 'Maximizing Federal Natural Gas Royalties', Interfaces 35, 38I-392.

Stückelberger, C.: 2002, Global Trade Ethics (WCC Publications, Geneva).

Suddaby, R., K.D. Elsbach, R. Greenwood, J.W. Meyer, and T.B. Zilber: 20I0, 'Organizations and Their Institutional Environments: Bringing Meaning, Values, and Culture Back In', Academy of Management Journal 6, I234-I240.

Suurs, R.A.A., M.P. Hekkert, S. Kieboom, and R.E.H.M. Smits: 2010, 'Understanding the Formative Stage of Technological Innovation System Development', Energy Policy 38(I), 4I9-432.

Swanson, D. L.: 1995, 'Addressing a Theoretical Problem by Reorienting the Corporate Social Performance Model', The Academy of Management Review 20(I), 43-64.

Taormina, R. J.: 2009, 'Organizational Socialization: The Missing Link Between Employee Needs and Organizational Culture', Journal of Managerial Psychology 24 (7), 650 - 676.

Tooby, J., and L. Cosmides: 1992, 'The Psychological Foundations of Culture', In J. Barkow, L. Cosmides, and J. Tooby (Eds.), The Adapted Mind: Evolutionary Psychology and the Generation of Culture (Oxford University Press, New York), pp.19-I36.

Tooby, J., and L. Cosmides: 2000, 'Mapping the evolved functional organization of mind and brain', In M.S. Gazzaniga (Ed.), The Cognitive Neurosciences. (MIT Press, Cambridge, MA), I I85-I 196. 
Tooby, J., L. Cosmides, and H.C. Barrett: 2003, 'The Second Law of Thermodynamics Is the First Law of Psychology: Evolutionary Developmental Psychology and the Theory Of Tandem, Coordinated Inheritances: Comment on Lickliter and Honeycutt (2003)', Psychological Bulletin The American Psychological Association, Inc. I29(6), 858-865.

Tylecote, A.: 2007, 'The Role of Finance and Corporate Governance in National Systems of Innovation', Organization Studies 28(I0), I46I-I48I.

Van de Ven, A. H.: 1986, 'Central Problems in the Management of Innovation,'

Management Science 32(5), 590 -607.

Velasquez, M. : 2005, Business Ethics: Concepts and Cases (Prentice-Hall, New Jersey).

Von Burg, U:: 200I, The Triumph of Ethernet: Technological Communities and the Battle for the LAN Standard (Stanford University Press, Stanford, CA).

Wasieleski, D. and S. Hayibor: 2009, 'Effects of the Use of the Availability Heuristic on Ethical Decision-Making in Organizations', Journal of Business Ethics 84(I), I5I- I65.

Weaver, G.R. and B.R. Agle: 2002, 'Religiosity and Ethical Behavior in Organizations: A Symbolic Interactionist Perspective', Academy of Management Review 27(I), 77-I02.

Weber, J., V.W. Gerde, and D.M. Wasieleski: 2008, 'A Blueprint for Designing an Ethics Program in an Academic Setting', In Diane Swanson and Dann G. Fisher (Eds.), Advancing Business Ethics Education, pp. 85-IOI. Charlotte, NC: Information Age.

Weick, K.E: 1979, The Social Psychology of Organizing, 2nd edition (Addison-Wesley, Reading, MA).

Werhane, P.H. 1994, 'The Normative/Descriptive Distinction in Methodologies of Business Ethics', Business Ethics Quarterly4(2), I75-I80.

Wilson, J. Q.: 1993, The Moral Sense (Free Press, New York).

Wood, D. J.: I99Ia, 'Corporate Social Performance Revisited', Academy of Management Review I6: 69I-718.

Wood, D. J. I99Ib, 'Social Issues in Management: Theory and Research in Corporate Social Performance', Journal of Management 17, 383-406.

Wood, D. J. and J. M. Logsdon: 2002, 'Business Citizenship: From Individuals to Organizations' Business Ethics Quarterly I2(3), 59-94.

Wu, A.D. and B.D. Zumbo: 2007, 'Understanding and Using Mediators and Moderators', Social Indicators Research 87, 367-392.

Yoshikawa, T., L.S. Tsui-Auch, and J. McGuire: 2007, 'Corporate Governance Reform as Institutional Innovation: The Case of Japan', Organization Science 18(6), 973-988.

Yuan, F., and R.W. Woodman: 2010, 'Innovative Behavior in the Workplace: The Role of Performance and Image Outcome Expectations', Academy of Management Journal 53(2): 323-342.

Zemansky, M.W.: 1937, Heat and Thermodynamics (McGraw-Hill Book Company, New York). 